\title{
OS PROFESSORES FORMADORES DO CURSO DE PEDAGOGIA DO SISTEMA ACAFE E A FORMAÇÃO CONTINUADA NA INCLUSÃO DE ACADÊMICOS COM DEFICIÊNCIA
}

\author{
Fabiana Ramos da Cruz Cardozo ${ }^{1}$, Sonia Maria Ribeiro ${ }^{2}$
}

\begin{abstract}
Resumo:
Este estudo visa conhecer, pelas vozes dos docentes de Pedagogia da Associação Catarinense das Fundações Educacionais - ACAFE, como ocorre a formação dos professores para a inclusão de estudantes com deficiência. Para isso, procedeu-se a uma abordagem qualitativa com a utilização de um questionário como instrumento para coleta de dados, configurando-se como uma pesquisa do tipo survey. Participaram 134 professores dos cursos de Pedagogia do Sistema ACAFE, atuantes em 2015 na modalidade presencial. Os principais achados revelaram notória quantidade de professores que afirmaram não ter mantido contato, na formação inicial, com conteúdos relacionados à inclusão. Evidenciou-se que suas necessidades formativas atuais estão especialmente relacionadas à legislação/teorias sobre inclusão/educação especial/ deficiência e didática/métodos de trabalho/estratégias de ensino. O estudo aponta para a formação continuada como um caminho que pode contribuir para a inclusão quando (re)constrói saberes e práticas docentes a partir de processos reflexivos permanentes acerca da função de ensinar.
\end{abstract}

Palavras-chave: Formação docente. Educação superior. Educação especial. Inclusão. Estudantes com deficiência.

1 Educadora; com graduação em Pedagogia (Habilitação em Ensino Fundamental e Educação Infantil), pela Universidade da Região de Joinville - Univille (2003), Especialização em MBA Gestão de Pessoas, pela Faculdade Padre João Bagozzi (2010), Graduação em Serviço Social, pelo Centro Universitário Leonardo Da Vinci (2014) e Mestrado em Educação, pela Univille (2015).

E-mail: fabiana.cardozo@gmail.com

2 Professora e Pesquisadora no Programa de Mestrado em Educaçãona Universidade da região de Joinville-UNIVILLE. Doutora em Educação pela Universidade Metodista de Piracicaba.

E-mail: soniaproesa@gmail.com 


\title{
THE ACAFE'S EDUCATION PROGRAM FACULTY AND IN-SERVICE TEACHER EDUCATION FOR THE INCLUSION OF STUDENTS WITH DISABILITIES
}

\author{
Fabiana Ramos da Cruz Cardozo, Sonia Maria Ribeiro
}

\begin{abstract}
:
This study aims to learn, from the Education program's faculty at the ACAFE Associação Catarinense das Fundações Educacionais, how the training of new teachers works for the inclusion of students with disabilities. In order to achieve this, a qualitative analysis was made of the results of survey-type data collection. 134 professors from ACAFE's 2015 Education on-site program faculty took part. The main findings revealed a significant number of college professors who claimed to not have had contact with inclusion-oriented content during their own training. It became evident that their current pedagogical shortcomings are especially related to the legal and theoretical aspects of inclusion, special education, didactics and disabilities, work methods and teaching strategies. This study points to in-service teacher education as a path that may contribute to inclusion by (re)building teacher's understandings and practices through repeated reflective processes on the object of teaching.
\end{abstract}

Keywords: Teacher Education. Higher Education. Special Education. Inclusion. Students with Disabilities. 


\section{Introdução}

Na última década (2000 a 2010), o número de matrículas de pessoas com deficiência na educação superior aumentou 933,6\%. Isto significa, em números absolutos, que os estudantes com deficiência passaram de 2.173, em 2000, para 20.287, em 2010, sendo que, desses, 6.884 estavam matriculados na rede pública e 13.403 na rede particular. (PORTAL BRASIL, 2014)

Pode-se relacionar esse aumento do número de matrículas ao processo de democratização do acesso à educação, como um todo, após a sua promulgação, como direito fundamental e de todos, na Constituição Federal (BRASIL, 1988). A partir desse processo, foram elaboradas leis, regulamentações e decretos com o foco na educação especial, que demandaram às instituições de educação superior uma obrigatoriedade no cumprimento dos princípios da educação inclusiva, visando o acesso e a permanência dos acadêmicos considerados como público-alvo da educação especial; que, de acordo com a Política Nacional de Educação Especial na Perspectiva da Educação Inclusiva (BRASIL, 2008), são estudantes com deficiência, transtornos globais do desenvolvimento e altas habilidades/superdotação. Neste estudo, será conferido um enfoque aos estudantes com deficiência; que, segundo Baptista (2011), têm uma prevalência numérica quando comparados aos demais estudantes, públicoalvo da educação especial.

Simultaneamente ao ingresso desses estudantes na educação superior, começou a se discutir e, aos poucos, realizar, processos de formação docente com o foco na inclusão e no trabalho junto aos referidos acadêmicos. $\mathrm{O}$ fato de a formação dos professores ter acontecido paralelamente à chegada dos estudantes com deficiência em sala de aula faz refletir sobre uma possível precarização, tanto do processo de inclusão quanto da formação dos docentes. Assim, conhecer como ocorre a formação inicial e continuada dos professores para a inclusão de estudantes com deficiência constitui-se como uma possibilidade investigativa relevante, que este artigo se propõe a realizar, a partir das vozes dos docentes de Pedagogia do Sistema ACAFE (Associação Catarinense das Fundações Educacionais).

\section{Formação continuada e inclusão na educação superior: perspectivas teóricas}

Nas políticas públicas com vistas à inclusão da pessoa com deficiência na educação superior, podem ser encontradas algumas diretrizes acerca da formação continuada para os profissionais da educação. A Lei de Diretrizes e Bases da Educação Nacional (BRASIL, 1996) expressa, no art. 62 (incluído pela Lei no 12.796/13), que:

[...] garantir-se-á formação continuada para os profissionais a que se refere o caput [trabalhadores em educação, portadores de diploma de curso técnico ou superior em área pedagógica ou afim], no local de 
Os professors formadores do curso de Pedagogia do sistema ACAFE e a formação continuada na inclusão de acadêmicos com deficiência

trabalho ou em instituições de educação básica e superior, incluindo cursos de educação profissional, cursos superiores de graduação plena ou tecnológicos e de pós-graduação. (BRASIL, 2013, s/p)

Conforme indicado na lei, a formação continuada é um direito e deve ser garantida para os profissionais da educação, dentre os quais figura o docente atuante na educação superior. Neste trabalho, utiliza-se um conceito de formação continuada como um “[...] processo de desenvolvimento da competência dos educadores, aqueles que têm como ofício transmitir - criando e reproduzindo - o conhecimento histórico e socialmente construído” (FUSARI;RIOS, 1995, p. 38).

Nota-se que o uso da expressão "processo de desenvolvimento" sugere uma ideia de formação que, longe de ser linear, trata-se de um movimento dialético e permanente, que se realiza ao longo do percurso profissional e pessoal de cada um. O termo "competência”, por sua vez, é entendido com base em Paulo Freire, para quem ser competente implica levar a sério a própria formação, estudando e se esforçando para estar à altura de sua tarefa (FREIRE, 2013).

Ainda que se considere adequado o conceito proposto por Fusari e Rios (1995) para definir formação continuada, não aparece, na definição dos autores, menção à questão da reflexão, que é considerada fundamental para se pensar o processo formativo docente. Isso porque, como expressou Nóvoa (2014), formar-se é, antes de tudo, refletir. No âmbito deste estudo, implica pensar sobre as questões que envolvem a docência na educação superior de forma consciente, intencional, coletiva e com o auxílio das teorias.

No que tange à formação continuada dos professores com foco na inclusão de acadêmicos com deficiência na educação superior, observa-se que, no Brasil, ainda persistem desafios, uma vez que entender educação como direito fundamental e de todos ainda é vivenciado como grande desafio para os professores (ZEPPONE, 2011).

Este desafio é problematizado por Romanowski (2012), que cita a falta de verbas, a estrutura espacial e didática inadequada, a incompatibilidade de horários e a dificuldade para a liberação do professor; diante da falta de profissionais para a sua substituição, como alguns dos motivos pelos quais há dificuldades na organização da formação continuada na educação como um todo. Para a mesma autora, "[...] no desempenho da profissão, o professor lida com interesses e culturas diversas” (ROMANOWSKI, 2012, p. 18) e, neste universo plural, tem a função de ensinar a estudantes com diferentes histórias de vida e que aprendem de formas diversas, o que torna o seu trabalho docente complexo. Por isso, conhecer as necessidades formativas dos professores é essencial para que a formação continuada seja bem sucedida, o que implica interagir com esses docentes e compreender as questões que "[...] envolvem as situações relativas aos alunos, aos currículos e aos [eles] mesmos" (ROMANOWSKI, 2012, p. 139).

Seria ingênuo pensar que a formação docente continuada se configure como um 
simples processo de repasse de conteúdos que abarquem todas as complexidades de seu trabalho. Essa formação excede esse modelo, uma vez que se trata de um processo evolutivo e continuado, demanda atenção ao desenvolvimento profissional e pessoal dos professores e valoriza o contexto em que estão inseridos, desde o momento histórico até a organização e gestão escolar. (ROMANOWSKI, 2012)

Assim, a formação continuada mostra-se como um caminho que possibilita refletir sobre o trabalho docente frente à diversidade e à inclusão do acadêmico público-alvo da Educação Especial, quando acessa os professores para conhecer suas necessidades formativas e, a partir delas, trabalha as demandas que emergem no contexto da educação superior.

De forma isolada, a formação continuada não garante que o trabalho do professor seja direcionado a assegurar a aprendizagem de todos os acadêmicos. Para que isso ocorra, há outros fatores envolvidos, desde aspectos culturais até questões subjetivas, pertinentes à história de vida de cada um. Por isso, torna-se necessário considerar o contexto em que o trabalho docente ocorre, observando as condições de trabalho, de acessibilidade, os recursos materiais e pedagógicos, assim como o projeto políticopedagógico da instituição. Esses fatores, dentre outros, impactam diretamente o processo de ensino e aprendizagem dos estudantes com e sem deficiência.

Sabendo, contudo, que a formação continuada é uma estratégia possível para endereçar os desafios vivenciados pelos docentes e demais profissionais da educação frente à tarefa de educar a todos, concorda-se com Arroyo (2007, p. 202) quando diz que "[...] pensar e construir políticas de formação para [a] diversidade pode ser tão desafiante quanto continuar apegados a modelos únicos de trabalho docente.” Na educação superior, por exemplo, algumas práticas institucionais parecem ter se perpetuado em uma lógica de reprodução. Como anteviram Tiffin e Rajasingham (2007, p. 32), “[...] continuaremos a oferecer diplomas, a usar títulos tradicionais, a trabalhar por semestres e a realizar rituais medievais em que os participantes se vestem como se arremedassem o refinamento medieval de monges para conferir o grau aos alunos."

Diante disso, revela-se um tensionamento nesta lógica da educação superior que é mantida e, ao mesmo tempo, precisa ser modificada para que possa lidar com o novo, o diferente, o heterogêneo, que se expressam não somente em relação a o acadêmico com deficiência, mas também nas diversas etnias, no gênero, na sexualidade e nos demais aspectos que fazem parte do contexto educacional.

Por isso, trazer para o contexto das instituições de educação superior a discussão sobre como os professores formados para atender um perfil homogêneo de alunos irão, na realidade, atender um perfil diverso e heterogêneo é uma maneira de criar espaços de formação com o compromisso de pensar formas menos excludentes e discriminatórias de educação (THOMA, 2006). Assim, efetivar nas universidades a educação como direito fundamental e de todos configura-se como um processo 
Os professors formadores do curso de Pedagogia do sistema ACAFE e a formação continuada na inclusão de acadêmicos com deficiência

complexo que, para ser entendido e praticado, demanda análise e contextualização a partir de suas múltiplas determinações, dentre as quais a formação docente continuada.

O tópico a seguir apresenta a metodologia utilizada neste estudo, incluindo aspectos epistemológicos, abordagem e tipo de pesquisa, instrumento para coleta de dados e método para análise destes.

\section{Percurso metodológico}

Relatar o percurso metodológico de uma investigação é contar o itinerário percorrido, desde a formulação da questão de pesquisa até o caminho efetivamente trilhado para respondê-la. Assim, uma vez definida a pergunta fundante deste estudo (Como ocorre a formação dos professores para a inclusão de estudantes com deficiência pelas vozes dos docentes de Pedagogia do Sistema ACAFE?), entendeu-se que a perspectiva histórico-cultural seria uma base epistemológica adequada para inspirar o processo de construção de conhecimento.

Essa perspectiva, cujas raízes estão fincadas no materialismo histórico-dialético, parte de uma visão do ser humano como "[...] ser ativo, social e histórico e [da] sociedade como produção histórica dos homens que, através do trabalho, produzem sua vida material.” (BOCK, 2007, p. 17). Logo, o principal objeto deste estudo - a formação docente continuada - é compreendida como um fenômeno social que, segundo Kosik (1976), se trata de um fato histórico, um momento de um determinado todo que só adquire verdade e concreticidade quando inserido nesse todo correspondente. Nesse sentido, não é possível analisar a formação continuada de professores sem associá-la ao contexto histórico, econômico e social em que é produzida.

Para esta pesquisa, escolheu-se a abordagem qualitativa, entendendo-a como adequada ao objetivo da investigação de compreender, pela voz dos professores, a formação docente para a inclusão de estudantes com deficiência na educação superior. Conforme Gatti e André (2010), esta abordagem constitui uma modalidade de investigação que toma por desafio a compreensão de aspectos formadores e formantes do humano, de suas relações e construções culturais, em suas dimensões pessoais, grupais ou comunitárias.

O método survey identifica o tipo deste estudo, uma vez que se procurou trabalhar com uma amostra significativa de professores de Pedagogia do Sistema ACAFE, composta por 134 respondentes. De acordo com May (2004), pesquisas do tipo survey consistem em uma maneira rápida e de baixo custo para identificar determinadas características de uma amostra expressiva.

O lócus da pesquisa foi a Associação Catarinense das Fundações Educacionais, conhecida como Sistema ACAFE, que consiste em uma entidade sem fins lucrativos que congrega 16 fundações educacionais (FURB, UDESC, UnC, UNESC, UNIARP, UNIBAVE, UNIDAVI, UNIPLAC, UNISUL, UNIVILLE, UNOCHAPECÓ, UNOESC, 
USJ, UNIVALI e CATÓLICA DE SANTA CATARINA), das quais 14 participaram deste estudo, por atenderem ao critério de inclusão de oferecer, no ano de 2015, o curso de Pedagogia, na modalidade presencial.

O processo de coleta de dados envolveu a aplicação de um questionário, enviado por correio a 431 professores e respondido, voluntariamente, por 134 deles. Para participar deste estudo, os professores deveriam ser atuantes na modalidade presencial do curso de Pedagogia do Sistema ACAFE, no ano de 2015.

O instrumento foi composto por 24 perguntas, das quais cinco foram utilizadas para este artigo, agrupadas em quatro questões conforme Quadro 1 a seguir:

\section{Quadro 1 - Perguntas do questionário sobre a Formação Docente para a Inclusão na Educação Superior}

\begin{tabular}{|c|l|}
\hline $\mathbf{0 1}$ & $\begin{array}{l}\text { Na formação acadêmica inicial, você teve contato com conteúdos referentes ao trabalho do } \\
\text { professor na inclusão de pessoas com deficiência? }\end{array}$ \\
\hline $\mathbf{0 2}$ & $\begin{array}{l}\text { As formações profissionais docentes, quando oferecidas, atendem suas necessidades para o } \\
\text { desenvolvimento do trabalho com os acadêmicos? }\end{array}$ \\
\hline $\mathbf{0 3}$ & $\begin{array}{l}\text { Considerando a formação continuada dos professores, aponte sugestões de temas específicos que } \\
\text { sejam relevantes no desenvolvimento do trabalho com acadêmicos com deficiência matriculados } \\
\text { nos cursos de Pedagogia das instituições que compõem o Sistema ACAFE. }\end{array}$ \\
\hline $\mathbf{0 4}$ & $\begin{array}{l}\text { A Instituição de Educação Superior (IES) em que você trabalha oferece formação específica } \\
\text { para inclusão dos acadêmicos com deficiência? + Quando a instituição não oferece formações } \\
\text { específicas, você as realiza de forma autônoma? }\end{array}$ \\
\hline
\end{tabular}

Fonte: Primária

Após a aplicação dos questionários, as respostas dos participantes foram organizadas em planilhas de Excel e analisadas conforme princípios da Análise de Conteúdo (BARDIN, 1977; FRANCO, 2012) e à luz de autores como Romanowski (2012), Libâneo (2004) e Garcia (1999). O método de Análise de Conteúdo, conforme Bardin (1977, p. 42) trata-se de um "[...] conjunto de técnicas de análise de comunicação visando obter, por procedimentos sistemáticos e objetivos de descrição do conteúdo das mensagens, indicadores quantitativos ou não que permitam a inferência de conhecimentos".

Nesse processo de análise, os principais indicadores que basearam a categorização dos dados foram: recorrência, complementaridade, contradição e relevância para o estudo da temática. Emergiram, então, quatro categorias de análise a priori, explicitadas no Quadro 2, abaixo: 
Os professors formadores do curso de Pedagogia do sistema ACAFE e a formação continuada na inclusão de acadêmicos com deficiência

Quadro 2 - Categorias de análise criadas a priori, a partir das perguntas do questionário

\begin{tabular}{|c|l|l|}
\hline $\mathbf{N}^{\mathbf{0}}$ & Perguntas do Questionário & Categorias de Análise \\
\hline $\mathbf{0 1}$ & $\begin{array}{l}\text { Na formação acadêmica inicial, você teve contato com } \\
\text { conteúdos referentes ao trabalho do professor na inclusão } \\
\text { de pessoas com deficiência? }\end{array}$ & $\begin{array}{l}\text { A formação inicial dos professores } \\
\text { de Pedagogia: presença/ausência de } \\
\text { conteúdos relacionados à inclusão }\end{array}$ \\
\hline $\mathbf{0 2}$ & $\begin{array}{l}\text { As formações profissionais docentes, quando oferecidas, } \\
\text { atendem suas necessidades para o desenvolvimento do } \\
\text { trabalho com os acadêmicos? }\end{array}$ & $\begin{array}{l}\text { Formações profissionais docentes } \\
\text { e o atendimento às necessidades } \\
\text { formativas dos professores }\end{array}$ \\
\hline $\mathbf{0 3}$ & $\begin{array}{l}\text { Considerando a formação continuada dos professores, } \\
\text { relevantes no desenvolvimento do trabalho com } \\
\text { acadêmicos com deficiência matriculados nos cursos } \\
\text { de Pedagogia das instituições que compõem o Sistema } \\
\text { ACAFE. }\end{array}$ & $\begin{array}{l}\text { Necessidades formativas docentes } \\
\text { para o trabalho junto a acadêmicos } \\
\text { com deficiência na educação superior }\end{array}$ \\
\hline $\mathbf{0 4}$ & $\begin{array}{l}\text { A Instituição de Educação Superior (IES) em que você } \\
\text { trabalha oferece formação específica para inclusão dos } \\
\text { acadêmicos com deficiência? + Quando a instituição } \\
\text { não oferece formações específicas, você as realiza de } \\
\text { forma autônoma? }\end{array}$ & $\begin{array}{l}\text { A formação dos professores para } \\
\text { inclusão dos acadêmicos com } \\
\text { deficiência: o papel da Instituição } \\
\text { de Educação Superior e do Professor }\end{array}$ \\
\hline
\end{tabular}

Fonte: Primária

Após Com relação ao perfil dos 134 participantes da pesquisa, pode-se dizer, a respeito da maioria deles, que: é representada pelo sexo feminino; possui entre 40 a 49 anos de idade; tem filhos; sua formação passou pela graduação, especialização e mestrado; não possui deficiência; atua como docente (no geral, não somente no curso de Pedagogia) há mais de 21 anos; e tem um regime de trabalho de até 10 horas semanais no curso de Pedagogia do Sistema ACAFE.

Assim, o próximo tópico traz a apresentação da análise e a discussão dos resultados encontrados.

\section{Análise e discussão dos resultados}

Neste tópico, serão abordados aspectos da formação inicial e continuada dos professores do curso de Pedagogia, no que se refere à inclusão de estudantes com deficiência na educação superior. A primeira categoria de análise versará sobre a presença ou ausência de conteúdos relacionados à inclusão na formação inicial dos professores de Pedagogia.

Sobre essa formação acadêmica inicial, a maioria dos docentes, representada por 77 (58\%) professores, respondeu que não teve contato com conteúdos relacionados ao trabalho do professor na inclusão de pessoas com deficiência. Com relação aos demais respondentes, 54 (40\%) informaram que tiveram esse contato, enquanto 3 
(2\%) não responderam.

Considera-se expressiva a quantidade de professores cuja formação inicial não abordou conteúdos relativos à inclusão. Emprestando a expressão de Arroyo (2011, p. 84), pode-se dizer que tal constatação indica, em uma primeira impressão, “[...] intranquilidades nos quintais do conhecimento" previsto nos currículos dos cursos de graduação. Porém, considerando que a maioria dos participantes da pesquisa estava, no ano ela ocorreu, com idade entre 40 e 49 anos, pode-se inferir que sua graduação foi anterior ou aconteceu durante o processo de democratização do acesso à escola e do movimento da educação inclusiva no Brasil, o que pode, em parte, explicar essa ausência.

Outro ponto de tensionamento que surgiu a partir deste dado foi a constatação de que há uma formação inicial genérica para uma atuação junto às singularidades humanas. $\mathrm{O}$ foco desta formação parece estar voltado a educar um todo homogêneo, e não a todos, como propõe a Constituição Federal (BRASIL, 1988). Como explanou Michels (2009, p. 150):

[...] mesmo tendo como máxima a educação inclusiva, a formação dos professores parece não caminhar nessa direção, uma vez que: a) aos professores especializados professores é destinada formação que centra no modelo médico-psicológico; b) aos professores regentes de classe é repassada essa formação, na maioria das vezes, assistemática; e c) os professores regentes de classe onde estão ‘incluídos’ os alunos considerados deficientes não são considerados prioridades nas propostas de formação.

Assim, enquanto a formação inicial ocorrer em moldes genéricos ou, ainda, focada em uma perspectiva clínica, a formação continuada continuará emergindo como uma - e por vezes, a única - possibilidade de dar conta do que é heterogêneo e singular no processo de ensino e aprendizagem. Não à toa tantos professores significam como "falta de formação" o constante não saber que os assombra no trabalho junto a estudantes público-alvo da Educação Especial. Martins (2009), por exemplo, concluiu que somente com estudos aprofundados e contínua reflexão é que os profissionais da educação conseguiriam derrubar as barreiras físicas, atitudinais e pedagógicas relacionadas ao público-alvo da Educação Especial e construir uma nova forma de perceber e atuar junto a eles.

Logo, se tais conteúdos não foram abordados na formação inicial, pode-se dizer que a necessidade de contemplá-los na formação continuada tornou-se incontestável. Isto porque a formação docente "[...] não termina com a sua diplomação na agência formadora, mas completa-se "em serviço”, como pontuou Diniz-Pereira (2006, p. 49). Nessa perspectiva, a formação continuada pode ser compreendida como um processo que possibilita ao professor o apoio necessário para que ele se desenvolva, à 
Os professors formadores do curso de Pedagogia do sistema ACAFE e a formação continuada na inclusão de acadêmicos com deficiência

medida que caminha em sua tarefa de educador, sem data fixa para terminar (DINIZPEREIRA, 2006). Nesse processo perene, os saberes docentes podem ser constituídos e/ou ressignificados, compondo um movimento reflexivo sobre a prática.

Dentre as respostas dos professores que relataram ter tido contato com conteúdos referentes à inclusão de estudantes com deficiência durante a graduação, P16 informou que tal conteúdo foi relativo à:

[...] Educação Especial - integração de portadores de necessidades especiais em sala de aula - adaptação de currículos e métodos. (P16)

Ao observar o uso das expressões "integração" e "portadores de necessidades especiais” no relato do participante, pode-se notar a presença de um paradigma integracionista em sua fala. Esse paradigma, ao mesmo tempo em que defende a democratização do ensino, a igualdade de direitos e a inserção de estudantes com deficiência no sistema educacional, também advoga que eles sejam encaminhados a instituições educacionais especializadas, dado o despreparo da escola comum para atendê-los. Ao fazê-lo, terminam por aceitar a segregação desses estudantes e assumem que o ensino regular não será para todos aqueles que são público-alvo da Educação Especial, mas apenas para aqueles que conseguem se adaptar. (BORGES; PEREIRA; AQUINO, 2012)

Nesse sentido, ressalta-se que, apesar do "[...] investimento na formação permanente dos professores [ser] fundamental para o processo de inclusão” (BORGES; PEREIRA; AQUINO, 2012, p. 8), o fato de discutir sobre ela nos momentos de formação continuada não garante que os docentes irão apropriar-se, de forma significativa, desse conteúdo. Também não assegura, por si só, que sua atuação seja direcionada à aprendizagem de todos os estudantes, com ou sem deficiência, pois o trabalho docente é implicado por questões que vão além da formação. Conforme salientado por Bernardes (2014), sobretudo quando exercido junto a estudantes com diferenças significativas no processo de escolarização, o trabalho docente tem se revestido de grande complexidade. A intensificação do trabalho docente, as condições em que ele é realizado, as legislações que o regulam, o momento de vida de cada professor e a cultura universitária são apenas alguns dos fatores que podem ser citados como influenciadores desse trabalho e, por conseguinte, do processo de ensino e aprendizagem.

Dentre o baixo número de professores que informaram ter tido acesso, durante a formação inicial, a conteúdos referentes à inclusão, o Quadro 3, a seguir, sinaliza os principais temas estudados, especificamente, por eles: 
Quadro 3 - Conteúdos referentes à inclusão abordados na formação acadêmica dos docentes pesquisados

\begin{tabular}{|c|c|c|}
\hline \multirow[t]{2}{*}{ Conteúdos referentes à inclusão abordados na formação inicial } & \multicolumn{2}{|c|}{ Recorrência } \\
\hline & Absoluto & Percentual \\
\hline Educação especial & 10 & $30 \%$ \\
\hline Linguagem/libras/braile & 8 & $24 \%$ \\
\hline Deficiências/transtornos/síndromes & 7 & $21 \%$ \\
\hline Fundamentos & 4 & $12 \%$ \\
\hline Metodologia & 4 & $12 \%$ \\
\hline Adaptação de currículo & 4 & $12 \%$ \\
\hline Disciplinas na graduação & 4 & $12 \%$ \\
\hline Dificuldades de aprendizagem & 4 & $12 \%$ \\
\hline Legislação & 4 & $12 \%$ \\
\hline Pessoa com deficiência & 3 & $9 \%$ \\
\hline Psicologia do excepcional & 3 & $9 \%$ \\
\hline Práticas de inclusão & 3 & $9 \%$ \\
\hline Acessibilidade & 2 & $6 \%$ \\
\hline Avaliação pedagógica e psicológica & 2 & $6 \%$ \\
\hline Psicopedagogia & 1 & $3 \%$ \\
\hline Fonoaudiologia & 1 & $3 \%$ \\
\hline Papel do segundo professor/instrutor/tradutor & 1 & $3 \%$ \\
\hline Conceito de inclusão & 1 & $3 \%$ \\
\hline
\end{tabular}

Fonte: Primária

Observa-se que“educação especial” foi o conteúdo mais citado (30\%) pelos docentes, sugerindo que o currículo da graduação, aparentemente, demonstra estar centrado na modalidade de ensino e não, por exemplo, na deficiência do aluno. Porém, adensando o olhar, pode-se verificar que 39\% dos conteúdos citados pelos docentes referiramse a “deficiências/transtornos/síndromes” (21\%), "pessoa com deficiência” (9\%) e "psicologia do excepcional” (9\%), o que revela um percentual significativo de formações que localizam a deficiência no estudante e a privilegiam quando o assunto em pauta é a inclusão.

Este enfoque na deficiência revela que:

[...] a formação de professores, no que se refere ao atendimento educacional de alunos com diagnóstico de deficiência, apresentase de maneira paradoxal, pois ainda encontramos uma formação 
Os professors formadores do curso de Pedagogia do sistema ACAFE e a formação continuada na inclusão de acadêmicos com deficiência

docente em uma perspectiva clínica como sustentação para o trabalho escolar com sujeitos com necessidades especiais, quando a proposta é desenvolver processos de escolaridade para esses sujeitos. (MICHELS, 2009, p. 151, grifo nosso)

Além disso, o foco na deficiência limita as possibilidades de compreensão do processo de escolarização como um todo, perdendo-se de vista sua complexidade. Reitera-se, portanto, a presença de um modelo médico-psicológico nas formações iniciais dos atuais professores dos cursos de Pedagogia que, por sua vez, têm a tarefa de formar novos profissionais da educação. Garcia (2007) é uma das autoras que aponta para as fragilidades desse modelo; que, segundo ela, contribuiu para produzir a exclusão na escola, por submeter a Educação Especial à lógica de um sistema educacional organizado de forma seriada, elitista e classificatória. Oliveira (2004) também denunciou os riscos de se imprimir à deficiência tamanho destaque na formação dos professores, advertindo que a estrutura organizacional e pedagógica da escola deixa de ser vista em sua inteireza, pois o olhar está voltado à “limitação” do aluno e não ao processo de escolarização como um todo.

Em síntese, pode-se dizer que os conteúdos sobre diversidade e inclusão, na maior parte dos casos, não foram abordados na formação inicial dos professores dos cursos de Pedagogia do Sistema ACAFE. Quando abordados, isso foi feito de forma genérica ou focada na deficiência do aluno, revelando a persistência de um paradigma médicopsicológico na formação docente para a inclusão.

Trazendo, agora, para a análise, o processo de formação continuada desses mesmos professores, foi possível constatar que 66 (49\%) informaram que não recebem, por parte da IES, formação para o trabalho junto a acadêmicos com deficiência, enquanto 62 (42\%) relataram que a IES oferece, sim, essa formação específica. Dentre esses últimos, 38 (81\%) apontaram que tais formações atendem às suas necessidades, enquanto docentes, para desenvolver o trabalho junto aos acadêmicos com deficiência.

Contudo, 24 (18\%) alertaram para o fato de que as formações, ainda que oferecidas pela IES, não atendem às suas necessidades formativas. Isso não significa que tais professores não vivenciem, em sua prática, desafios relacionados à inclusão. Antes disso, significa que os desafios existem e as formações oferecidas não têm contribuído para endereçar suas necessidades e promover as reflexões necessárias para reverem suas práticas; relativas a ensinar aos alunos público-alvo da Educação Especial.

Isto reforça, como expressou Imbernón (2010, p. 53), que a formação continuada “[...] deve agir sobre as situações problemáticas dos professores”, partindo delas, e não de demandas genéricas. Conhecer as necessidades formativas dos docentes e pensar as formações a partir delas constitui um meio de afirmar uma “[...] crença na capacidade dos professores de formularem questões válidas sobre sua própria prática e de definirem objetivos que tratem de responder tais questões.” (IMBERNÓN, 2010 
p. 57)

Nesse sentido, cabe refletir sobre o quanto as necessidades formativas dos docentes são ou não conhecidas pelas instituições em que eles atuam. Pensando nisso e reconhecendo que “a formação pode contribuir para a melhoria da educação” (ROMANOWSKI, 2012, p. 184), apresentam-se como as principais necessidades formativas dos professores de Pedagogia do Sistema ACAFE, no que concerne ao trabalho junto a acadêmicos com deficiência: 71 (52\%) Legislação, Teorias sobre inclusão, Educação Especial e Deficiência; 51 (38\%) Didática, Método de trabalho e Estratégia de Ensino, 10 (7\%) Aceso e Acessibilidade e 4 (3\%) Adaptação Curricular.

O levantamento das necessidades formativas constitui uma condição imprescindível para desenvolver ações de formação continuada que estejam alinhadas aos desafios vivenciados na prática docente. Este, segundo Romanowski (2012), é um dos princípios dos programas de formação continuada: fornecer respostas para as necessidades de desenvolvimento profissional apontadas pelos professores.

Quando a formação nasce do trabalho e, mais especificamente, pela voz dos professores, das situações complexas e desafiadoras que dele emergem, pode-se dizer que há, de fato, protagonismo dos docentes em seus processos formativos. Também pode-se aduzir que tais processos, nessa lógica, baseiam-se em necessidades reais e singulares dos docentes e não em “[...] problemas genéricos, uniformes, padronizados, [...] que se [supõem] comuns aos professores.” (IMBERNÓN, 2010, p. 53)

Na voz dos professores pesquisados, as principais necessidades formativas em prol do enfrentamento dos desafios relacionados à inclusão de acadêmicos com deficiência mostraram-se relacionadas à Legislação/Teorias sobre Inclusão, Educação Especial e Deficiência e, em segundo lugar, relativas Didática/Método de Trabalho/Estratégia de Ensino.

Parece haver, por parte dos professores, uma necessidade de se aproximar do que está posto em documentos oficiais sobre educação especial, bem como de conhecer a produção teórica existente sobre inclusão, educação especial e deficiência. O posicionamento dos docentes, nesse sentido, reforça a necessidade de que a prática esteja vinculada à teoria e confere ao processo de formação continuada um lugar de destaque para que essa aproximação aconteça. Como explicou Silva (2014, p. 923), “[...] os professores necessitam que as ações de formação continuada promovam uma aproximação entre teoria e prática e que suas expectativas e necessidades de formação sejam tomadas como ponto de partida no momento de planejar essas ações.”

Ao sinalizarem questões relacionadas à didática como uma necessidade formativa, pode-se dizer que, provavelmente, os professores reconhecem, em seus métodos e estratégias de ensino, uma possibilidade de alavancar os processos de aprendizagem e desenvolvimento dos estudantes com deficiência. Quando o foco está no modo de ensinar do professor, e não somente na forma de aprender do estudante, identifica-se 
Os professors formadores do curso de Pedagogia do sistema ACAFE e a formação continuada na inclusão de acadêmicos com deficiência

um espaço para que a universidade possibilite meios alternativos de ensinar o estudante com deficiência, quando as fórmulas já conhecidas ou tradicionais não conseguem dar conta de promover aprendizagem. Isso porque, como explicou Vigotski (2010, p. 863), “[...] caminhos indiretos de desenvolvimento são possibilitados pela cultura quando o caminho direto está impedido. [...] O desenvolvimento cultural seria, assim, a principal esfera em que é possível compensar a deficiência.”

Com a clareza da existência dessas necessidades, foi perguntado aos professores se, quando a IES não oferecia a formação continuada, eles a realizavam, ou não, de forma autônoma, ou seja, por conta própria, com ou sem investimento financeiro, seja através de cursos on line, presencial, individual ou em grupo. Em resposta, 80 (60\%) professores afirmaram que realizam a formação continuada por conta própria quando a IES não oferece, 38 (28\%) apontam que não realizam e 16 (12\%) não responderam ao questionamento.

Chama a atenção que mais da metade dos docentes tenha sinalizado que a formação continuada é realizada de forma autônoma. Esse processo de aprendizagem autônoma, segundo Marcelo Garcia (1999), inclui atividades de formação nas quais a própria pessoa toma a iniciativa e remete a um estilo independente de aprender, com capacidade de tomar decisões, articular normas e limites, autogerir-se e confiar na própria experiência. Referindo-se a processos formativos docentes, Demartini (2008, p. 46) destacou que "refletir sobre a própria vida - experiências, formação, projetos, sonhos, frustrações, sucessos, insucessos, sentimentos etc. - é tarefa sugerida já há vários anos por especialistas em formação de educadores como experiência que pode configurar-se como transformadora da prática pedagógica.” Essa autonomia dos professores, nos leva a duas importantes reflexões: a necessidade de que as instituições invistam no processo de formação dos professores, e o comprometimento desses professores com o seu trabalho, uma vez que buscam por conta própria os aprimoramentos capazes de auxiliá-los no seu trabalho com acadêmicos.

Assim, a formação continuada pode ser pensada como um itinerário de reflexão permanente para a (re)constituição de saberes e fazeres docentes. Trata-se de uma estratégia que pode favorecer o processo de desenvolvimento profissional docente, bem como o processo de aprendizagem de todos os estudantes, com ou sem deficiência. No entanto, ainda que se aposte na formação continuada como uma estratégia para promover o desenvolvimento profissional docente, é preciso que as estruturas e condições de trabalho dos docentes possibilitem que essa formação encontre expressão em momentos de reflexão e prática. Como salientou Agapito (2013), ainda que se reconheça a vital importância da formação continuada, não se pode esperar somente do professor, ou de sua formação, todas as soluções para os problemas da educação. 


\section{Considerações Finais}

No intuito de concluir, mas não extinguir, as discussões aqui realizadas sobre o processo de formação continuada dos professores da educação superior com vistas à inclusão de acadêmicos com deficiência, introduz-se, aqui, questionamento levantado por Arroyo (2011, p. 229): “[...] por que essa mania tão estendida de criar espaços próprios de formação, de debate e de diálogo? Temos tantos cursos oficiais de requalificação, passaram tantos anos nas escolas de magistério, nos cursos oficiais de licenciatura, de pedagogia [...] O que pode expressar essa atitude?”

O próprio autor procura responder tal questionamento indicando que essa necessidade de se formar continuamente, tão expressiva por parte dos professores, pode indicar que eles não encontram, na educação formal (por exemplo, na graduação e pós-graduação) apenas e nos cursos de aperfeiçoamento disponíveis, uma formação nascida da prática e direcionada ao atendimento das reais necessidades formativas docentes.

Tal constatação reitera que os processos de formação que mais contribuem para o desenvolvimento profissional dos professores “[...] são aqueles que oferecem uma continuidade do processo formativo, que contemplam as experiências deles, onde podem socializar os sucessos e as dificuldades e que lhes propiciem reflexões sobre sua prática, em um espaço coletivo de aprendizagens.” (SILVA, 2014, p. 923)

Os docentes pesquisados, ao manifestarem que sua principal necessidade formativa, para o trabalho junto a acadêmicos com deficiência, é relativa às teorias/legislações sobre educação especial, inclusão e deficiência, tornam possível perceber um distanciamento entre teoria e prática, que reforça o imperativo de que sejam criados espaços próprios de formação em serviço.

Em síntese, este estudo contribui para afirmar a importância e a necessidade de investimento na formação docente, visto que, quando essa formação é realizada continuamente, constitui-se como uma forma de reflexão sobre o trabalho que permite revisitar aspectos da profissionalidade docente na educação superior e rever modos e modelos de atuação. Também possibilita uma análise sobre os desafios e complexidades que envolvem a docência junto a acadêmicos com deficiência na educação superior, uma vez que se tenha, como ponto de partida, a voz e as necessidades formativas dos professores, sendo a captação dessas vozes, ou seja, a devolutiva dos questionários respondidos pelos docentes pesquisados, o maior desafio deste estudo, levando a pensar com mais acurácia sobre o compromisso dos próprios docentes em relação aos estudos e às pesquisas científicas do nosso país.

\section{Referências}

AGAPITO, Juliano. A formação inicial de professores na perspectiva da educação 
Os professors formadores do curso de Pedagogia do sistema ACAFE e a formação continuada na inclusão de acadêmicos com deficiência

inclusiva: um olhar para a diversidade. Dissertação de Mestrado. 195 f. 2013. Universidade da Região de Joinville, Joinville.

ARROYO, Miguel González. Condição docente, trabalho e formação. In: SOUZA, João Valdir. (Org.). Formação de professores para a educação básica: 10 anos de LDB. Belo Horizonte: Autêntica, 2007, p. 191-209.

. Ofício de mestre: imagens e autoimagens. 13. ed. Petrópolis, RJ: Vozes, 2011.

BAPTISTA, Claudio Roberto. Ação pedagógica e educação especial: a sala de recursos como prioridade na oferta de serviços especializados. Rev. bras. educ. espec., 2011, v. 17 , n. 1 , p. 59-76.

BARDIN, L. Análise de conteúdo. 70. ed. Lisboa: Portugal, 1977.

BERNARDES, Cleide Aparecida Hoffmann. O trabalho docente no Atendimento Educacional Especializado pelas vozes de professoras especializadas. Dissertação de Mestrado. 179 f. 2014. Universidade da Região de Joinville, Joinville.

BOCK, Ana Mercês Bahia. A psicologia sócio-histórica: uma perspectiva crítica em psicologia. In: ; GONÇALVES, Maria da Graça Marchina; FURTADO, Odair. Psicologia sócio-histórica: uma perspectiva crítica em psicologia. 3. ed. São Paulo: Cortez, 2007.

BORGES, Maria Célia; PEREIRA, Helena de Ornellas Sivieri; AQUINO, Orlando Fernández. Inclusão versus integração: a problemática das políticas e da formação docente. Revista Ibero-americana de Educação (online), 2012, v. 3, n. 59, p. 1-11.

BRASIL. Constituição da República Federativa do Brasil. Promulgada em 05 de outubro de 1988. Brasília, DF: 1988.

. Ministério da Educação. Secretaria de Educação Especial. Política Nacional de Educação Especial na Perspectiva da Educação Inclusiva. Brasília, DF: 2008.

. Lei $n^{\circ}$ 9.394, de 20 de dezembro de 1996. Estabelece as diretrizes e bases da educação nacional. Brasília, DF: 1996. Disponível em: <http://www.planalto.gov.br/ ccivil_03/leis/L9394. htm>. Acesso em: 12 set. 2016.

. Lei $n^{\circ} 12.796$, de 4 de abril de 2013. Altera a Lei no 9.394, de 20 de dezembro de 1996, que estabelece as diretrizes e bases da educação nacional, para dispor sobre a formação dos profissionais da educação e dar outras providências. Brasília, DF, 2013

DEMARTINI, Z. B. F. Das histórias de vida às histórias de formação. In: SOUZA, 
E. C.; MIGNOT, A. C. V. (Orgs.) História de vida e formação de professores. Rio de Janeiro: Quartet, FAPERJ, 2008, p. 39-64.

DINIZ-PEREIRA, Júlio Emílio. Formação de professores: pesquisas, representações e poder. 2. ed. Belo Horizonte: Autêntica, 2006.

FRANCO, Maria Laura Puglisi Barbosa. Análise de conteúdo. 4. ed. Brasília: Liber Livro, 2012.

FREIRE, Paulo. Pedagogia da autonomia: saberes necessários à prática educativa. 47. ed. Rio de Janeiro: Paz e Terra, 2013.

FUSARI, José Cerchi; RIOS Terezinha Azerêdo. A educação do educador em serviço: o treinamento de professores em questão. São Paulo: Cortez, 1998.

GARCIA, Carlos Marcelo. Formação de professores: para uma mudança educativa. Porto, Portugal: Porto Editora, 1999.

GARCIA, Rosalba Maria. O conceito de flexibilidade curricular nas políticas públicas de inclusão educacional. In: JESUS, D. M. et. al. (Orgs.). Inclusão, práticas pedagógicas e trajetórias de pesquisa. Porto Alegre: Mediação/Prefeitura Municipal de Vitória/ CDV/FACITEC, 2007.

GATTI, Bernadete Angelina; ANDRÉ, Marli Eliza. A relevância dos métodos de pesquisa qualitativa em educação no Brasil. In: WELLER, Wivian; PFAFF, Nicolle. (Org.). Metodologias da pesquisa qualitativa em educação: teoria e prática. Petrópolis, RJ: Vozes, 2010, p. 29-38.

IMBERNÓN, Francisco. Formação continuada de professores. Porto Alegre: Artmed, 2010.

KOSIK, Karel. Dialética do concreto. 2. ed. Rio de Janeiro: Paz e Terra, 1976.

LIBÂNEO, José Carlos. Organização e gestão da escola: teoria e prática. 5. ed. Goiânia: Alternativa, 2004.

MARTINS, Lúcia de Araújo Ramos. Formação continuada de docentes: algumas reflexões sobre a sua contribuição para a educação inclusiva. In: BAPTISTA, Claudio Roberto; JESUS, Denise Meyrelles. (Org.). Avanços em políticas de inclusão: o contexto da educação especial no Brasil e em outros países. 2. ed. Porto Alegre, RS: Mediação, 2011, p. 153-174.

MAY, Tim. Pesquisa social: questões, métodos e processos.3. ed. Porto Alegre: 
Os professors formadores do curso de Pedagogia do sistema ACAFE e a formação continuada na inclusão de acadêmicos com deficiência

Artmed, 2004

MICHELS, Maria Helena. Paradoxo da formação docente na política de educação inclusiva do Estado de Santa Catarina: a perspectiva clínica como sustentação do trabalho escolar. In: BAPTISTA, Claudio Roberto; JESUS, Denise Meyrelles. (Org.). Avanços em políticas de inclusão: o contexto da educação especial no Brasil e em outros países. 2. ed. Porto Alegre, RS: Mediação, 2011, p. 139-152.

OLIVEIRA, I. A. Saberes, imaginários e representações na educação especial: a problemática ética da “diferença” e da exclusão social. 2. ed. Petrópolis, RJ: Vozes, 2004.

PORTAL BRASIL. Matrículas de pessoas com deficiência em universidades cresceram 933\% em dez anos (2014). Disponível em: <http://www.brasil.gov.br/educacao/2012/10/ ensino-superior-do-brasil-tem-recorde-de-matriculas-nos-ultimos-anos $>$. Acesso em: 09 jun. 2016.

ROMANOWSKI, Joana Paulin. Formação e profissionalização docente. Curitiba: InterSaberes, 2012.

SILVA, Valdicléa Machado da. Ações de formação continuada: necessidades formativas e fontes de aprendizagens docentes nos anos iniciais do Ensino Fundamental. Dissertação de Mestrado. 2014. Universidade da Região de Joinville, Joinville.

THOMA, Adriana da Silva. A inclusão no ensino superior: “- ninguém foi preparado para trabalhar com esses alunos (...) isso exige certamente uma política especial”. Trabalho apresentado na $29^{a}$ Reunião Nacional da ANPEd, GT 15 - Educação Especial. Caxambu, MG: 2006. Disponível em: <http://29reuniao.anped.org.br/trabalhos/ trabalho/GT15-2552--Int.pdf>. Acesso em: 03 jun. 2016.

TIFFIN, J.; RAJASINGHAM, L. A universidade virtual e global. Porto Alegre, RS: Artmed, 2007.

VIGOTSKI, Lev S. A defectologia e o estudo do desenvolvimento e da educação da criança anormal. Educ. Pesqui., 2011, v. 37, n. 4, p. 863-869.

ZEPPONE, Rosimeire Maria Orlando. A conferência mundial de educação para todos e a declaração de Salamanca: alguns apontamentos. Rev. Educ. Espec., 2011, v. 24, n. 41, p. 363-376.

Recebido em: 08/11/2016

Aprovado em: 26/02/2019 